\title{
O FUTURO DO EMPREGO E O PROFISSIONAL DO FUTURO ${ }^{1}$
}

\section{THE FUTURE OF EMPLOYMENT AND THE PROFESSIONAL OF THE FUTURE ${ }^{1}$}

\author{
José Dimas Ramos Mota Junior ${ }^{1 *}$, Dra. Elisa Maria Andrade Brisola² \\ ${ }^{1}$ Mestrando pelo Programa de Pós-graduação em Desenvolvimento Humano: Formação, Políticas e Práticas Sociais da Universidade \\ de Taubaté, Taubaté, SP, Brasil, dimasmotajr@gmail.com \\ ${ }^{2}$ Doutora em Serviço Social pela Pontifícia Universidade Católica de São Paulo. Professora do Programa de Pós-graduação em \\ Desenvolvimento Humano: Formação, Políticas e Práticas Sociais da Universidade de Taubaté-SP, Brasil e do Programa de Gestão e \\ Desenvolvimento Regional do UNIS-MG-Brasil, elisabrisola@gmail.com \\ * Autor para correspondência
}

\begin{abstract}
Resumo
Pensar no profissional do futuro tem sido uma das principais preocupações individuais e coletivas nos últimos anos. A indústria que até então era fonte dos "melhores" empregos, com o advento da 4a Revolução Industrial, parece precisar cada vez menos da mão de obra humana. Nesse contexto, o Fórum Econômico Mundial publicou, em 2018, o relatório intitulado "O Futuro dos Empregos", no qual compila dados e opiniões dos maiores empregadores mundiais acerca do futuro dos empregos, as exigências e adaptações necessárias para atender aos requisitos da 4a Revolução Industrial. As análises e cenários traçados tinham um horizonte temporal de 5 anos (2018-2022), porém após o início da crise, em decorrência da pandemia de COVID-19, um novo relatório foi publicado com o mesmo nome, formato e horizonte de tempo (2020-2025). Esse artigo utiliza a metodologia de pesquisa bibliográfica para trazer uma leitura crítica do relatório de 2018, bem como sua comparação com o relatório de 2020. Os dados contidos nos relatórios com relação ao Brasil são colocados para um recorte local e identificação da situação nacional. Conclui-se que os dados dos dois relatórios são uteis para as análises, contudo em uma análise crítica questiona-se a abrangência dos grupos pesquisados, assim como a perspectiva positiva do relatório de 2018, reduzida em 2020 ainda que mantido o viés positivo. Por fim, ponderamos que os problemas que a 4a Revolução Industrial já vem causando pelo mundo podem se agravar, principalmente em países como o Brasil que tem historicamente questões como por exemplo a desigualdade social que pode se aprofundar no contexto estudado.
\end{abstract}

Palavras-chave: Futuro do Emprego. 4ำ Revolução Industrial. Desemprego. Políticas Públicas.

\begin{abstract}
Thinking about the professional of the future has been one of the main individual and collective concerns in recent years. The industry that until then was the source of the "best" jobs, with the advent of the 4th Industrial Revolution, seems to need less and less human labor. In this context, the public World Economic Forum, in 2018, the report entitled "The Future of Jobs", in which it compiles data and opinions of the world's largest employers of the future of jobs, the requirements and adaptations required to meet the requirements of the 4th Industrial Revolution. The analyzes and scenarios outlined have a time horizon of 5 years (2018-2022), but after the beginning of the crisis, as a result of the COVID-19 pandemic, a new report was published with the same name, format and time horizon (2020-2025). This article uses the bibliographic research methodology to bring a critical reading of the 2018 report, as well as its comparison with the 2020 report. The data contained in the reports in relation to Brazil are mentioned for a local cut and identification of the national situation. It is concluded that the data from the two reports are useful for the analyzes, however in a critical analysis the scope of the groups surveyed is questioned, as well as a positive perspective of the 2018 report, reduced in 2020 even though the positive bias is maintained. Finally, we consider that the problems that the 4th Industrial Revolution has already caused around the world may worsen, especially in countries like Brazil that have historically had issues such as, for example, social inequality that may deepen in the studied context.
\end{abstract}

Keywords: Future of Employment. 4th Industrial Revolution. Unemployment. Public policy.

(C)UNIS-MG. All rights reserved. 


\section{INTRODUÇÃO}

O índice de desemprego no Brasil é medido pelo Instituto Nacional de Geografia e Estatística (IBGE), sendo realizado por meio da Pesquisa Nacional por Amostra de Domicílios Contínua (PNAD) e se refere às pessoas com idade para trabalhar que não estão trabalhando, mas estão disponíveis e tentam encontrar trabalho. Conforme a pesquisa no último trimestre de 2019 o índice de desemprego alcançou $11,0 \%$ da População Economicamente Ativa do Brasil (PEA) (BRASIL, 2020).

O índice de desemprego é um importante dado/parâmetro sobre a situação do emprego no país, mas não retrata as variáveis que estão associadas aos problemas associados. Na verdade, a questão do emprego é uma preocupação individual e coletiva de boa parte da população mundial compartilhada entres as regiões ricas e pobres do globo terrestre, guardadas as diferenças econômicas, sociais e regionais.

Nesse sentido, o presente trabalho tem o objetivo de avaliar a questão do emprego com enfoque no futuro, ou seja, o que esperar do futuro do emprego? O que se exigirá dos profissionais do futuro? Qual será o impacto sobre o emprego tem em vista a 4a Revolução Industrial? A literatura atual traz algumas reflexões sobre essas e outras questões, porém ainda com poucos trabalhos, sobretudo em português, em um enfoque humano. Nesse cenário, esse artigo parte de uma leitura crítica ao relatório "O Futuro dos Empregos" produzido pelo Fórum Econômico Mundial em 2018, bem como traz a comparação com sua nova versão publicada em outubro de 2020, a partir da qual se seleciona alguns indicadores e os compara com a literatura existente.

\section{MÉTODO}

O presente trabalho foi realizado por meio de uma revisão bibliográfica, utilizando-se, principalmente como referência à leitura crítica do relatório "O Futuro dos Empregos" publicado em 2018 pelo Fórum Econômico Mundial e republicado com o mesmo nome em 2020. Além disso foi realizado coleta de dados nos bancos de dados: SciELO e Banco de teses e dissertações e periódicos da CAPES (Coordenação de Aperfeiçoamento de Pessoal de Nível Superior). Os descritores escolhidos e utilizados para a pesquisa foram: 4ㅇ Revolução Industrial e Desemprego. O período abarcado foi de 5 anos (2020-2015) e adicionado o filtro "em português". Foram encontrados somando as duas bases 54 e 776 publicações. A seleção final se deu relacionando adicionalmente a questão da COVID-19 o que limitou a quantidade de artigos dado que o assunto ainda é bastante novo.

\section{RESULTADOS E DISCUSSÕES}

Antes do início da análise do Relatório "O Futuro dos Empregos", publicado em 2018 pelo Fórum Econômico Mundial, cabe refletir sobre a 4a Revolução Industrial, bem como seus impactos e significados.

A palavra "revolução" remete-se às mudanças bruscas e radicais e, de fato, ao longo da história, as novas tecnologias e as novas formas de ver o mundo por elas permeado vêm desencadeando mudanças profundas nos sistemas econômicos e na estrutura social (SCHAWAB, 2016).

A "primeira revolução industrial", ocorrida entre 1760 e 1840 produziu mudanças advindas da invenção do motor a vapor, das ferrovias e da produção mecânica. A "segunda revolução industrial", iniciada no final do século XIX e início do século XX, foi marcada pela invenção da 
eletricidade e da linha de montagem, o que possibilitou a produção em massa, popularizada por Henry Ford, por meio das linhas de montagem e a divisão do trabalho, que foram derivadas do sistema de organização do trabalho de Frederick W. Taylor. Já a "terceira revolução industrial", desencadeada na década de 60 do século XX, é a chamada de computador e revolução digital, iniciada com a computação de mainframe (computadores de grande porte), evoluindo até a computação pessoal e chegando à internet (SCHAWAB, 2016).

Ainda para Klaus Schwab (2016, p. 11 e 12, livre tradução), "atento às várias definições e argumentos acadêmicos usados para descrever as três primeiras revoluções industriais, acredito que hoje estamos no início de uma quarta revolução industrial". Para o autor essa revolução é uma revolução digital caracterizada por uma internet mais onipresente e móvel, por sensores (chips) mais rápidos e mais baratos, por aprendizado de máquina e por inteligência artificial.

A integração tecnológica da Indústria 4.0 está permitindo aumento representativo de produtividade, ao mesmo tempo que, permite uma customização dos produtos em atendimento às necessidades cada vez mais específicas dos clientes.

Conforme Lima et al. (2019), o conceito Indústria 4.0 surgiu pela primeira vez em 2011, durante a feira Hannover Messe, sediada em Hanôver na Alemanha. Desse período em diante, a Indústria 4.0 se desenvolveu rapidamente e hoje se destacam várias tecnologias presentes nesse contexto, tais como: Cyber-Physical Systems (CPS), a Internet of Things (IoT), a Internet of Services (IoS), robótica avançada, impressão 3D, inteligência artificial, Big Data, computação em nuvem e nanotecnologia. Evidentemente, cabe esclarecer que desde os primórdios da industrialização esse processo vem passando por mudanças profundas, com a implementação cada vez mais sofisticada de inovações tecnológicas e mudanças nas formas de gestão do trabalho, reverberando na diminuição da oferta de postos de trabalho.

\subsection{O Relatório "O Futuro dos Empregos"}

O relatório "O Futuro dos Empregos" (The Future of Jobs Report), do Fórum Econômico Mundial (sigla de WEF - da abreviatura do inglês World Economic Forum), foi resultado de um aperfeiçoamento e continuidade do trabalho de pesquisa que, em 2016, havia produzido um primeiro relatório sobre o mesmo tema, denominado "O futuro dos empregos: emprego, habilidades e estratégia da força de trabalho para a quarta revolução industrial".

Para a produção do relatório de 2018 , o WEF realizou uma pesquisa no primeiro semestre do mesmo ano, com a comunidade global de membros do referido Fórum concentrando-se nas opiniões dos executivos de negócios, sobretudo Diretores de Recursos Humanos, que estão no centro das mudanças do mercado de trabalho.

O conjunto de dados do Relatório é composto de 313 respostas únicas dos representantes das empresas participantes. Essas empresas representam 15 milhões de empregos diretos. A base regional de dados é composta por dados de 20 economias desenvolvidas e emergentes do mundo, que representam 70\% do PIB mundial (WEF, 2018).

O Relatório é estruturado em duas partes: onde primeira explora o futuro dos empregos, tarefas de trabalho, habilidades e estratégias da força de trabalho no período de 2018 a 2022, abordando, primeiramente, uma série de tendências esperadas e, em sequência, as questões consideradas prioritárias, encerrando-se com um conjunto de recomendações. Na segunda parte, apresentam-se as tendências detalhadas com informações de diversos setores e de cada país pesquisado. 
No prefácio, escrito pelo presidente executivo do WEF, Klaus Schwab, são ponderadas as "enormes" oportunidades advindas da 4a Revolução Industrial e recomendações sobre o caminho para o aproveitamento dessas oportunidades: isto é, como catalisar resultados positivos e um futuro de bom trabalho para todos, o que exigirá liderança ousada e espírito empreendedor de empresas e governos, além de uma mentalidade ágil de aprendizado ao longo da vida dos funcionários (WEF, 2018, p. V, livre tradução).

O prefácio termina com a manifestação do que é esperado pelo WEF nas palavras do presidente executivo: "Esperamos que este relatório seja um apelo à ação de governos, empresas, educadores e indivíduos, a fim de aproveitar uma janela que se fecha rapidamente para criar um novo futuro de bom trabalho para todos" (WEF, 2018, p. VI, livre tradução).

O Quadro 1, traz as "principais conclusões" do relatório, que são levantamentos de perspectivas extraídas da pesquisa base do relatório, onde nota-se uma ênfase na implantação de novas tecnologias ( $85 \%$ das empresas pesquisadas vão implantar novas tecnologias até 2022), o relatório também aponta para uma "nova fronteira" entre homem e máquina (estimou-se que em 2022, 42\% das atividades sejam realizadas por máquinas, em 2018 esse número era de 29\%). As perspectivas apontam também para uma nova "geografia de produção", onde, segundo o relatório, $74 \%$ das empresas vão considerar a presença de talentos locais ao se instalarem. As perspectivas levantadas também indicam para uma mudança no "tipo" dos empregos, segundo os dados $50 \%$ das empresas esperam reduzir sua força de trabalho em tempo integral até 2022, além disso pretende-se manter e expandir estratégias atuais, como a terceirização por exemplo. As "habilidades" necessárias para os trabalhos do futuro vão sofrer uma constante instabilidade e os dados apurados indicam que $54 \%$ dos funcionários vão precisar de qualificação ou requalificação até 2022. No levantamento feito pelo relatório chama atenção a perspectiva positiva de geração de empregos, segundos os dados apresentados, 75 milhões de empregos podem ser deslocados por uma mudança na divisão do trabalho entre humanos e máquinas, enquanto 133 milhões de novos papéis podem surgir (WEF, 2018). O WWE conclui ainda que:

\begin{abstract}
Finalmente, os formuladores de políticas, os reguladores e os educadores precisarão desempenhar um papel fundamental para ajudar aqueles que são deslocados a redirecionar suas habilidades ou treinar novamente para adquirir novas habilidades e investir pesadamente no desenvolvimento de novos alunos ágeis em futuras forças de trabalho, abordando melhorias na educação e sistemas de treinamento, além de atualizar a política trabalhista para corresponder às realidades da Quarta Revolução Industrial (WEF, 2018, p. IX, livre tradução).
\end{abstract}

\title{
3.2 O Relatório "O Futuro dos Empregos" comparativo versão 2018 e 2020
}

No ano de 2020, o mundo foi acometido pela pandemia do Covid-19, doença infecciosa causada pelo Corona vírus. Este novo vírus e a doença eram desconhecidos antes do início do surto em Wuhan, na China, em dezembro de 2019 (OMS, 2020). A pandemia do Corona vírus expõe ainda mais as desigualdades sociais no que tange a renda e trabalho.

Sem um tratamento específico para a Covid-19, a estratégia adotada em um primeiro momento foi "distanciamento social". Para tanto foi necessário decretar o fechamento e a paralisação de muitas empresas.

As ações colocadas em prática dificultaram, portanto, o fluxo de bens, de serviços e, principalmente, de pessoas. As previsões do impacto são um grande desafio, uma vez que a pandemia da COVID-19 tem ritmo e intensidade diferentes em cada parte do mundo. Além disso, o tamanho da contração econômica poderá ser diferente dos exemplos históricos (FERREIRA JR; SANTA RITA, 2020). 
Esse contexto fez com que o Fórum Econômico Mundial organizasse um novo relatório sobre o futuro dos empregos, revisando o anterior, que a princípio contemplaria um período de cinco (5) anos, mas que, dadas as novas condições, precisou ser atualizado. O novo relatório foi divulgado em outubro de 2020 com o mesmo nome do primeiro, trocando-se apenas o ano e, assim como o primeiro, "traça" as perspectivas para um período de 5 anos (2020-2025).

O novo relatório já no seu prefácio pondera uma "inadequação" nos atuais contratos sociais e uma necessidade de revisão e pondera que a crise está impactando sobretudos as comunidades que "já estavam em desvantagem". Contudo o relatório (assim como o primeiro) vê espaço para um otimismo desde que ocorra uma grande mobilização em escala nacional e regional com a participação pública e privada em "escala e velocidade" sem precedentes (WEF, 2020).

O Quadro 1, traz alguns pontos de comparação entre os dois relatórios:

Quadro 1 - Comparativo Principais Conclusões Relatórios WEF 2018/2020.

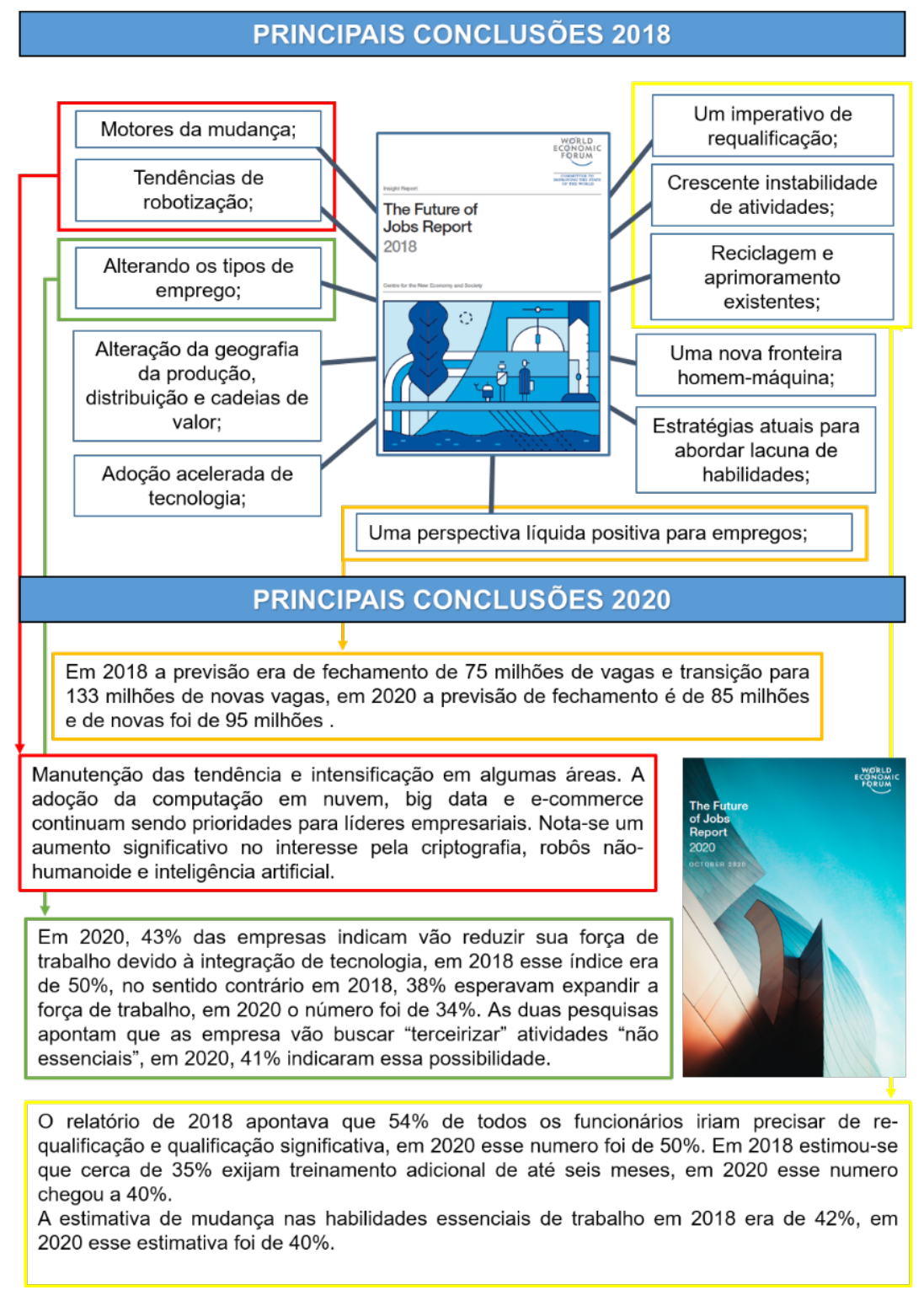

Fonte: Elaborado pelos autores

Conforme os dados apresentados no Quadro 1, nota-se que algumas das perspectivas do novo relatório são muito parecidas e vão no mesmo sentido que o primeiro. Alguns dados numéricos dos dois levantamentos são tão próximos que sugerem uma manutenção dentro da 
margem de erro matemática, por exemplo quanto a expansão/redução da força de trabalho ou a necessidade de requalificação tiveram uma variação pequena entre as duas pesquisas, assim sugerem uma manutenção das expectativas com relação a esses itens.

Destaca-se na comparação novamente a questão da perspectiva positiva de geração de empregos, que apesar de uma redução, se manteve positiva em 2020. O relatório pondera que a recessão de 2020 criou um "novo normal", alterando a maneira como a Quarta Revolução Industrial vai alterar o mercado de trabalho, mas ainda assim, pondera que "poucos especialistas propõem que a ruptura tecnológica levará a redução de oportunidades" (WEF, 2020, p. 9, livre tradução). Entretanto, o "otimismo" do relatório 2018 parece estar "abalado" na versão de 2020, pois reconhece que, mesmo com a manutenção das perspectivas positivas a geração de empregos, parece estar "começando a ficar para trás destruição - e este fator está prestes a afetar trabalhadores desfavorecidos com particular ferocidade" (WEF, 2020, p. 49, livre tradução).

O relatório de 2020 traz ainda algumas ponderações acerca de que o futuro do trabalho já chegou para alguns trabalhadores, no que se refere ao "trabalho remoto", por exemplo. Segundo os dados durante a crise do Corona vírus, $44 \%$ dos trabalhadores foram capazes de trabalhar remotamente e que, atualmente, a "parcela teórica" de trabalhadores que podem exercer suas atividades remotamente é de $38 \%$ nos países de "alta-renda", $25 \%$ nos de "média" e de $13 \%$ nos de baixa. Esta porcentagem pode ser ainda menor se colocado um novo fator, como o "acesso à internet", por exemplo (WEF, 2020).

Segundo o próprio relatório, esse cenário aprofunda as desigualdades nos mercados de trabalho na medida que aceleram e aprofundam as mudanças trazidas pela Quarta Revolução Industrial (WEF, 2020, p. 9).

A crise do COVID-19 está expondo ainda falhas em nossas estruturas econômicas, sobretudo em virtude das consequências de um longo período de perda do poder de barganha dos trabalhadores e, novamente aqui, os benefícios que poderiam ser colhidos com as novas tecnologias não serão acessíveis a todos, dado que o trabalho remoto não é uma opção para a maioria dos trabalhadores (MAZZUCATO, 2020).

As "conclusões" dos dois relatórios também apresentam similaridades principalmente no que se refere ao apoio governamental na requalificação e na formação da força de trabalho, porém, pode-se observar algumas mudanças de postura ou de ênfase, por exemplo, nas conclusões da versão de 2018, o papel da "responsabilidade pessoal" do trabalhador em sua formação é dado como "inquestionável", no entanto, não aparece nas conclusões de 2020.

A questão do apoio governamental embora presente nas conclusões das duas versões, vem com muita ênfase na versão de 2020, inclusive sugerindo que "políticas públicas" deveriam ser criadas nesse sentido e que na "medida que os números do desemprego aumentem, é cada vez maior a urgência em expandir a proteção social" (WEF, 2020, p. 49, livre tradução).

\subsection{O Brasil nos relatórios}

O relatório da WEF de 2018, como dito anteriormente, é estruturado em duas seções, nessa estrutura coube a segunda seção trazer, dentre outros, dados detalhados dos países e regiões pesquisadas. O relatório da WEF de 2020 tem a mesma estrutura. Dessa maneira, é possível visualizar com a interpretação desses dados, as tendências e o impacto da COVID-19, segundo a visão dos pesquisados.

No que se refere à adoção de determinadas tecnologias, os relatórios demonstram que, segundo a expectativa dos pesquisados, haverá uma intensificação na implantação destas como, 
por exemplo: a implantação de soluções de uso de dados em "nuvem", que em 2018 aparecia em 69\% das respostas, em 2020 estava em 97\%; o uso de análise de "Big-data", que em 2018 já aparecia em 92\% das respostas e em 2018 apareceu em 97\%; quanto a soluções de criptografia para segurança de dados a expectativa subiu de $61 \%$ para $94 \%$; quanto a "internet das coisas" foi de 79\% para 94\%; a respeito do uso de "inteligência artificial" a expectativa foi de 79\% para 94\%. Em todos os itens abordados (inclusive os que não foram aqui citados) houve um aumento significativo na expectativa de implantação das novas tecnologias entre os relatórios (WEF, 2018, p. 72 - 73 e WEF, 2020, p. 71- 72).

Conforme citado no tópico anterior (item 3.2) e no Quadro 1 os dois relatórios apontam para a necessidade de requalificação e qualificação da força de trabalho.

Quanto à questão da requalificação, mais especificamente no tempo estimado como necessário para sua realização, o comparativo dos dados dos dois relatórios sugere um aumento desse tempo, bem como aumento do grupo de trabalhadores que precisam ser requalificados. A versão de 2018 por exemplo aponta que $47 \%$ da força de trabalho não precisaria de requalificação, esse número nem aparece em 2020, pois o total dos dados estão encaixados com a necessidade de algum tempo de requalificação, ou seja, toda a mão de obra vai precisar de requalificação.

Já em relação à quantidade de tempo estimada, também podemos notar a intensificação dessa necessidade, por exemplo: em 2018 a estimativa era que 12\% precisariam de menos de um mês de treinamento. em 2020 esse número foi de $21,4 \%$, o intervalo de mais de um mês até um ano (na pesquisa divididos em: 1 a 3, 3 a 6 e 6 a 12 meses) de necessidade de treinamento era em 2018 de 33\%, em 2020 esse número subiu para 57,60\% e, por fim, o número de trabalhadores que vai precisar de mais de um ano em 2018, era 9\%, chegou a 21\% em 2020 (WEF, 2018, p. 72 - 73; WEF, 2020, p 71 - 72).

Os dados, quanto ao tempo de requalificação tiveram um crescimento razoável na expectativa nesse curto período transcorrido entre os dois relatórios, os intervalos das necessidades de tempo receberam numericamente a expectativa que antes estava concentrada em trabalhadores que não precisariam de requalificação.

A diferença e a aceleração das tendências apontadas nos dados de implantação de tecnologias e tempo necessário de requalificação demonstram que para os pesquisados a situação do Brasil mudou razoavelmente no período de dois anos (2018 e 2020) e que as expectativas agora já refletem os impactos trazidos pela crise ocasionada pela pandemia de COVID-19.

Para analisar um pouco a tendência do impacto da COVID-19, o relatório de 2020 apresenta respostas dadas quanto as expectativas das empresas de estratégias de enfrentamento as decorrências da crise (Quadro 2). Note-se que a soma de todas as porcentagens é maior que $100 \%$ (Quadro 2), pois os respondentes poderiam escolher uma ou mais alternativas. As estratégias mais frequentes foram: "acelerar a digitalização do processo de trabalho", que aparece em $92 \%$ das respostas, e que é uma solução ligada ou até uma preparação para a segunda estratégia, a qual trata-se de "fornecer oportunidades de trabalhar remotamente", com $88 \%$ das respostas. Outro dado importante é que $52 \%$ das respostas apontam para "acelerar a digitalização da qualificação / requalificação", ou seja, existe uma tendência de responder à necessidade de requalificação com o uso de ferramentas digitais. 
Quadro 2 - Impacto da COVID-19 na estratégia das empresas.

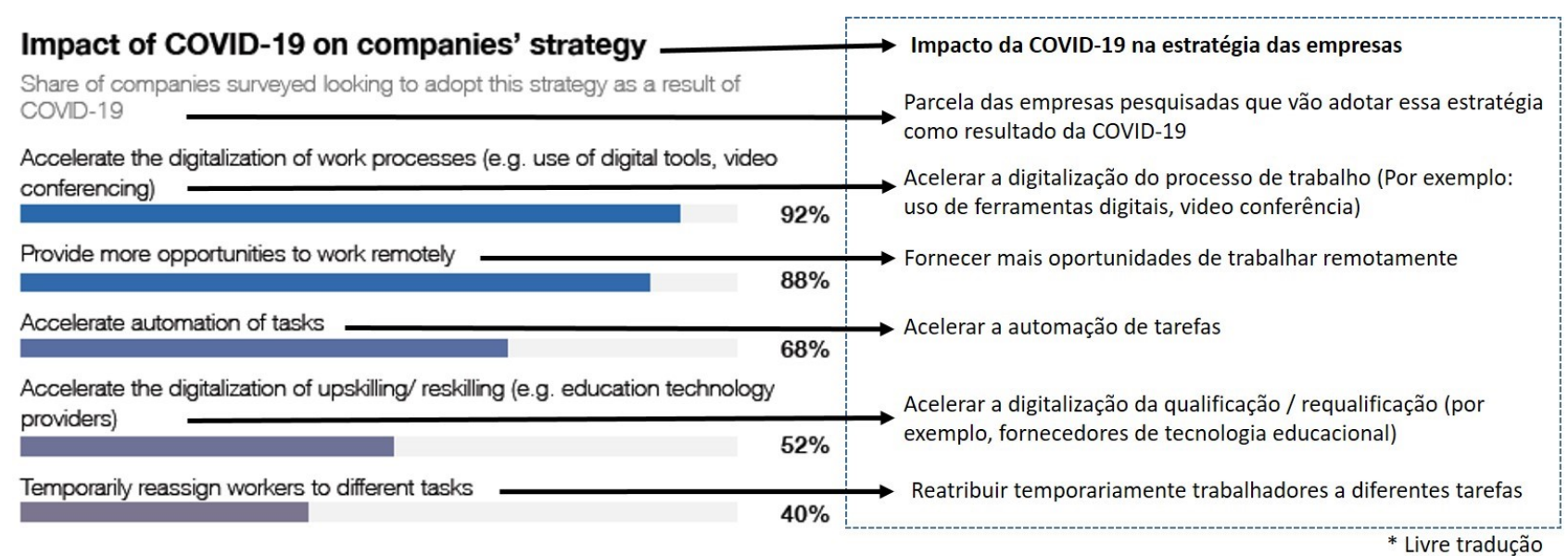

Fonte: WEF, 2020, pag. 71.

\subsection{Problematizações necessárias}

O futuro é uma incerteza em qualquer área, ainda assim, o exercício de reflexão, mais do que uma tentativa de previsão, é uma estratégia de planejamento. Nesse sentido, as duas versões do relatório da WEF são uma importante ferramenta estratégica para planejamento e antecipação de tendências. Entretanto, mesmo com a ponderação acerca da importância dos relatórios e até para um exercício dialético, pondera-se que algumas das afirmações e dados precisam ser lidos criticamente.

A primeira ponderação se refere ao público-alvo da primeira pesquisa, que foi extremamente elitizado, ou seja, a pesquisa baseou-se na opinião de diretores das maiores empresas mundiais, que concentram "15 milhões de trabalhadores", porém, como o próprio relatório aponta um universo de "3 bilhões de trabalhadores". A justificativa para o público da pesquisa é que essas grandes corporações servem como "âncoras" das economias locais. Tal justificativa, em parte pode ser verdadeira, pois as grandes corporações têm grande poder de influência, principalmente na fase atual de concentração que se encontra o capitalismo, mas, deve-se considerar dois importantes fatores: a) apesar da globalização, as diferenças locais são grandes e as "tendências" vão impactar as mais diversas sociedades de diferentes maneiras; b) o argumento de que as grandes empresas podem influenciar o rumo do mercado de trabalho desmonta um dos principais argumentos otimistas da 4 o Revolução Industrial, qual seja, 0 aumento da autonomia e da qualidade de vida do trabalhador, no chamado "trabalho-digital".

Para Caruso (2018, p. 386), "todos os elementos que definem os aspectos positivos do trabalho digital e a 'virada do conhecimento' no trabalho são controversos", isso porque existem dois tipos de trabalhadores: os mais qualificados terão um maior poder de negociação da sua força de trabalho, enquanto os menos qualificados terão ainda mais pressão sobre sua situação, ocasionando uma insegurança e redução da renda média.

Outra importante ponderação feita pelo WEF na primeira e segunda versão do relatório é quanto ao potencial de geração de empregos que a 4을 Revolução Industrial supostamente possui. Existem alguns fatores complicadores no quadro positivo apresentado pelo WEF: primeiro com relação à comparação com outras revoluções, pois há de se considerar que a velocidade dessa é muito maior, tanto que a primeiro verão preparada para um período de 5 anos precisou ser revista no segundo ano, claro que isso foi causado pelo impacto não esperado da crise da COVID-19, mas que demonstra novamente a "fragilidade" dessa perspectiva otimista. A comparação dos dois relatórios comprova essa fragilidade na medida em que a redução numérica da perspectiva 
positiva é significativa, passando de 58 milhões para 10 milhões, de possíveis novos empregos. Além disso, temos que considerar que o próprio relatório de 2020 em suas conclusões aponta que esse dito saldo positivo parece estar "ficando para trás".

As recomendações do WEF de aprimoramento dos trabalhadores, contidas nas duas versões, ao longo da carreira e do apoio dos governos para esse fim vão sofrer com os aspectos locais, afinal as novas habilidades requeridas de caráter "cognitivo", por exemplo, que são desenvolvidas na primeira infância precisaria de uma educação de base de qualidade, e em países em desenvolvimento, como o Brasil, essa ainda é questão a se resolver.

A necessidade de apoio governamental é ponderada nas duas versões do relatório (2018 e 2020) mas aparece com uma ênfase muito maior na versão 2020, inclusive sugerindo desenvolvimento de políticas públicas e de uma visão "holística" dos governos ao qual cobram uma e expansão da proteção social. Nesse ponto, o relatório vai ao encontro com a estratégia que parece ser a principal para o enfrentamento das decorrências da COVID-19 em diversas áreas, ou seja, a expansão da proteção social dada pelo Estado que volta ao protagonismo depois um período em que esse foi duramente questionado pela agenda neoliberal. "Infelizmente, na última década, muitos países aplicaram medidas de austeridade, como se a dívida pública fosse o problema. O resultado foi o enfraquecimento das mesmas instituições públicas que necessitamos para superar crises como a pandemia do Corona vírus" (MAZZUCATO, 2020).

Ainda para MAZZUCATO (2020) esse apoio estatal tem que ser estruturado para impedir erros do passado recente:

Não se trata de postergar ou impedir o apoio estatal, mas de estruturá-lo corretamente. Temos que evitar os erros da era pós-2008, quando os programas de resgate permitiram às corporações aumentar ainda mais seus lucros, assim que a crise terminou, mas não assentaram as bases para uma recuperação sólida e inclusiva (MAZZUCATO, 2020).

É importante ponderar que a necessidade de apoio governamental também é um aspecto que carrega em si o problema o problema da desigualdade, a final a crise é mundial, mas a capacidade para a solução dos problemas é regional e algumas regiões vão sofrer o impacto mais do que as outras nos mais diversos aspectos, seja com relação ao "futuro dos empregos" seja em questões mais estruturais de saúde pública por exemplo.

Portanto, levando-se em consideração os argumentos da WEF, agravados pelas decorrências da crise do COVID-19, pode-se "temer" que a 4ㅇ Revolução Industrial se transforme em mais um mecanismo de aumento das desigualdades características do modo de produção capitalista.

Na Europa esse novo mercado de trabalho tem exposto a população mais jovem a empregos mal remunerados e más condições de trabalho, com altos níveis de instabilidade (CARUSO, 2018). Isso em um período anterior à crise do COVID-19 onde essas desigualdades parecem estar sendo ampliadas. Se as novas condições impostas aos trabalhadores têm tido um efeito negativo na Europa, continente tradicionalmente mais economicamente desenvolvido, qual seria o resultado esperado nos países subdesenvolvidos ou em desenvolvimento?

Caruso (2018) traz uma interessante e atual conclusão sobre a 4ํ Revolução Industrial (ao qual chama de "revolução digital") até o presente momento:

[...] toda a transformação geralmente chamada "revolução digital" até agora não alcançou nenhuma de suas promessas. A organização do trabalho não se tornou mais horizontal, e sim mais parcial e formal. Os trabalhadores não aumentaram seu poder de decisão ou sua autonomia. O trabalho tornou-se mais criativo apenas para uma fração de trabalhadores altamente qualificados (CARUSO, 2018, p. 389, livre tradução). 
O que se pode claramente observar é a reprodução da velha receita do capitalismo, ou seja: redução dos salários e garantias dos trabalhadores, redução do poder de "barganha" da força de trabalho, aumento na capacidade de monitorar e avaliar o desempenho do trabalho e aumento na capacidade de monitorar e avaliar o desempenho. Razões essas que levam a crer que o cenário não é favorável a reversão dessa situação sobretudo para os trabalhadores (CARUSO, 2018).

\section{CONSIDERAÇÕES FINAIS}

Como podemos observar o cenário é "pouco animador" para os trabalhadores particularmente no Brasil, pois tem-se além das altas taxas de desemprego, questões estruturais ainda não superadas, como, por exemplo, o acesso à educação primordial para desenvolvimento das habilidades requeridas do trabalhador moderno.

Os relatórios analisados indicam as contradições que as novas formas de reprodução capitalista, associadas às velhas, deixam enormes contingentes de trabalhadores sobrantes os quais não mais serão funcionais para tal reprodução porque não atendem ao perfil exigido com a implementação de tecnologias mais complexas.

No contexto da pandemia do COVID-19 tal realidade se agudiza colocando desafios tanto para o Estado, empresários e a sociedade em geral, exigindo a reflexão acerca dos rumos da sociedade brasileira contemporânea e também das gerações de trabalhadores do futuro.

\section{REFERÊNCIAS}

BRASIL, IBGE. Painel de Indicadores, 2020. Disponível em: <https://www.ibge.gov.br/indicadores>. Acesso em: abr. 2020.

CARUSO, L. Digital innovation and the fourth industrial revolution: epochal social changes? Al \& Soc 33, 379-392, 2018. Disponível em: <https://doi.org/10.1007/s00146-017-0736-1>. Acesso em: abr. 2020.

COLLINS, R. Technological Displacement and Capitalist Crises: Escapes and Dead Ends. Political Conceptology, 1, 23-34, 2010. Disponível em: <http://politconcept.sfedu.ru/2010.1/05.pdf>. Acesso em: abr. 2020.

FERREIRA JR, R. R; SANTA RITA, L. P. Impactos da Covid-19 na Economia: limites, desafios e políticas. Cadernos de Prospecção, v. 13, n. 2, Edição Especial COVID-19, 2020.

LIMA, A. G. de; PINTO, G. S. INDÚSTRIA 4.0: um novo paradigma para a indústria. Interface Tecnológica - v. 16 n. 2 (2019). Disponível em <https://revista.fatectq.edu.br/index.php/interfacetecnologica/article/view/642/433>. Acesso em: abr. 2020.

MARCONI, M. D. A.; LAKATOS, E. M. Fundamentos de Metodologia Científica. 8. ed. São Paulo: Atlas S.A., 2019.

MARQUES, A. P; CHAVES, MI; SERRA, H. e U. Paula. Introdução - Imaginar "futuros" do trabalho, contextos e vivências subjetivas. Configurações [Online], 24, 2019. Disponível em: <http://journals.openedition.org/configuracoes/7620>. Acesso em: abr. 2020. 
MAZZUCATO, M. Capitalism's Triple Crisis. Project Syndicate, [S.I.], 2020. Disponível em: https://www.project-syndicate.org/commentary/covid19-crises-of-capitalism-new-state-role-bymariana-mazzucato-2020-03. Acesso em: 03 maio 2020.

OMS - ORGANIZAÇÃO MUNDIAL DE SAÚDE. 2020. Disponível em: https://www.who.int/emergencies/diseases/novel-coronavirus-2019. Acesso em: 03. maio. 2020.

TESSARINI, G.; SALTORATO, P. Impactos da indústria 4.0 na organização do trabalho: uma revisão sistemática da literatura. Revista Produção Online, Florianópolis, v. 18, n. 2, p. 743-769, 2018.

WEF, World Economic Forum. Future of Jobs: Employment, Skills and Work force Strategy for the Fourth Industrial Revolution. 2016. Disponível em:

<http://www3.weforum.org/docs/WEF_Future_of_Jobs.pdf>. Acesso em: abr. 2020.

WEF, World Economic Forum. The Future of Jobs Report. 2018. Disponível em:

<https://www.weforum.org/reports/the-future-of-jobs-report-2018>. Acesso em: nov. 2020.

WEF, World Economic Forum. The Future of Jobs Report. 2018. Disponível em:

<https://www.weforum.org/reports/the-future-of-jobs-report-2020>. Acesso em: abr. 2020.

SCHWAB, Klaus. The Fourth Industrial Revolution. Genebra: World EconomicForum, 2016.

${ }^{1}$ Uma versão reduzida deste artigo foi publicado no VI Congresso Internacional da Rede ACINNET 2020.

${ }^{1}$ A shortened version of this paper was published at the VI ACINNET Network Conference 2020. 